\title{
Performance Analysis of Red Chilli in a Hybrid Collector with Solar Dryer
}

\author{
E Murali ${ }^{1}$, P Sivamurugan ${ }^{2}$ and B Srimanickam*3 \\ 1,2,3*Vel Tech Rangarajan Dr. Sagunthala R\&D Institute of Science and Technology, Chennai - 62, India. \\ srima1980@gmail.com*
}

Article History: Received: 10 November 2020; Revised: 12 January 2021; Accepted: 27 January 2021; Published online: 05 April 2021

\begin{abstract}
This article performed various analysis on Red chilli by hybrid collector with solar dryer (HCSD). This study was carried out forced convection solar dryer which performed better in all aspects such as drying time, moisture removal rate, electrical efficiency, electrical thermal efficiency, thermal efficiency and overall thermal efficiency. In general, solar radiation was provided a sources of generating energy to drive a solar dryer. Hybrid collector has been provided the electrical and thermal energy to run a solar dryer. The solar dryer was tested by drying $12 \mathrm{~kg}$ of red chilli in the drying air temperature in the range of $32{ }^{0} \mathrm{C}-56{ }^{0} \mathrm{C}$. The initial moisture content of the red chilli was $71.5 \%$ (weight basis) and was reduced to the final moisture content of 16.2 $\%$ (weight basis) in 6 consistent days with clear sunny days. The HCSD was operated between 9 hrs to 16 hrs. Finally, comparative study was also handled for better understanding in HCSD, in which solar dryer drying made better outcome than open sun drying.
\end{abstract}

Keywords: Hybrid Collector, Solar Dryer, Red Chilli, Electrical and Thermal Efficiency.

\section{Introduction \& Literature Reviews}

In recent years, Non-conventional energy sources are significantly reliable among primary, secondary and tertiary sectors. Because it has eco-friendly, pollution free, compare to conventional power which is significantly better adaptive nature to all the terrain. However, it has its own demerits such as less efficiency, more capital investment and less outcome. Among the all renewable energy resources solar energy is remarkably better in all aspects. When solar panel temperature were attained at higher level which can be reduced its electrical performance. Due to this drawbacks, air, water, oil and nano fluids were used as a coolant medium to enhance its electrical and thermal efficiency.

The enhancing the solar panel temperature by $1^{\circ} \mathrm{C}$ was known to cause $0.5 \%$ decrement in electrical efficiency for silicon cells [ $1-3]$. Investigated the performance of solar collector with V-groove. Author claimed that V-groove is more efficient than traditional geometrical roughness. [4 - 8]. Srimanickam et al. [9] analysed the various air channels in photovoltaic thermal hybrid system. It concluded that thermal, equivalent thermal and overall thermal efficiency were found to be $18.9 \%, 36.5 \%$ and $48.8 \%$ respectively. Srimanickam et al. [10] assessed the performance of single glazing flat plate solar photovoltaic thermal hybrid system. It concluded that electrical and electrical thermal efficiency have been attained $12.40 \%$ and $34.43 \%$, respectively.

Srimanickam et al. [11] studied the various performances of photovoltaic thermal hybrid system such as electrical, thermal and exergy. Srimanickam et al. [12] have investigated energy and exergy efficiency of various air channels configurations with two types of air mass flow rates through experimentally. The results show that electrical, thermal and exergy efficiency were obtained $13.9 \%, 25.9 \%$ and $49.4 \%$ respectively. Srimanickam et al. [13] have performed five types of mild steel air channels with two kinds of mass flow rates by experimentally. The results were found that electrical and thermal efficiencies were attained $14.27 \%$ and $20.81 \%$ respectively. Yadav et al. [14] enriched the heat transfer area in the air channel with rectangular roughness on the absorber surface.

Investigated various geometrical roughness with baffles on the absorber plate which claimed better performance than without baffles [15 - 21]. Sawhney et al. [22] investigated various wavy winglet vortex roughness on the absorber plate and found the thermohydraulic performances. Dongxu Jin et al. [23] Performed the different geometrical shape of $\mathrm{V}$ shaped ribs on the absorber plate and attained better thermal performance. Deep Singh Thakur et al. [24] studied the artificial roughened hyperbolic ribs such as rectangular, triangular and semi-circular on the absorber plate of the solar air heater. Hans et al. [25] executed the broken arc rib roughness geometry on the absorber plate which influenced better performance than nil roughness geometry. Adem et al. [26] investigated circular ring turbulators with various hole geometries on the absorber plate of the solar air collector.

Anil et al. [27] investigated the multiple arc shaped aluminum wire roughness on the absorber plate. Omer and Zala. [28] Investigated air based PVT collector by experimentally. Author ascertained that electrical and 
thermal efficiency was attained $20 \%, 44 \%$ respectively when the mass flow rate was enhanced in the range of 0.024 to $0.057 \mathrm{~m} 3 / \mathrm{s}$. Slimani et al., [29] studied the flowing of air behind absorber surface which generating better thermal energy in the Algiers climatic conditions. Hasanuzzaman et al. [30] studied as the glazing temperature upsurges the performance of electrical energy of the PV system recedes significantly. On account of this, maximum electrical energy of the PV system could be attained by extracting the heat through circulation of air, water or mixed of both. As per the above cited literature none of the journal has not reported hybrid collector with solar dryer for red chilli. The objective of this journal has been provided comparative study of solar drying and open sun drying with a specific location and also found better electrical, electrical thermal, thermal and overall thermal efficiency.

\section{Experimental Details}

The flat plate Solar Air collector with dryer is a distinct kind of heat exchangers. In general, sun shine falls on the solar panel that transforms solar energy or photo energy or light energy into heat energy. Top surface of solar panel absorbs the incoming solar radiation and convert it into heat energy and electrical energy simultaneously. Then heat energy transfers to a moving fluid that fluid travels from inlet duct to outlet duct of air passage. The experimental set-up is designed and tested at Chennai $\left(13.0827^{\circ} \mathrm{N}, 80.2707^{\circ} \mathrm{E}\right)$. Chennai is situated in South India where has a grand potential of receiving solar energy due to its location in the tropical region. The external dimensions of hybrid collector is $1115 \mathrm{~mm}$ x $670 \mathrm{~mm}$. The experimental setup of solar air collector with dryer is shown in Fig. x. This system consists of solar collector, fan, drying chamber and aluminium roof air venthot fluid air comes from the solar collector which feeds to the drying chamber with the help of small fan. The moisture of red chilli with in the drying chamber were evaporated with the help of thermal energy.

As a result, moisture were removed from the red chilli which makes into dry chilli subsequently. In this research work, moisture content, temperature of the red chilli, pressure of the drying chamber, air velocity and other related energy measurements were utilized for testing the complete setup. Relative humidity and temperature of red chilli in the drying chamber were monitored with the help of various sensors which were mounted at the selected location of the drying chamber. Solar panel were wedded with air channel medium which was tilted $13^{\circ}$. The inclination of solar collector is designed in a way to extract more absorbed energy from the incident solar intensity. Experimental readings were taken between 9 am to 4 pm with a regular interval of 30 minutes for all the test days.

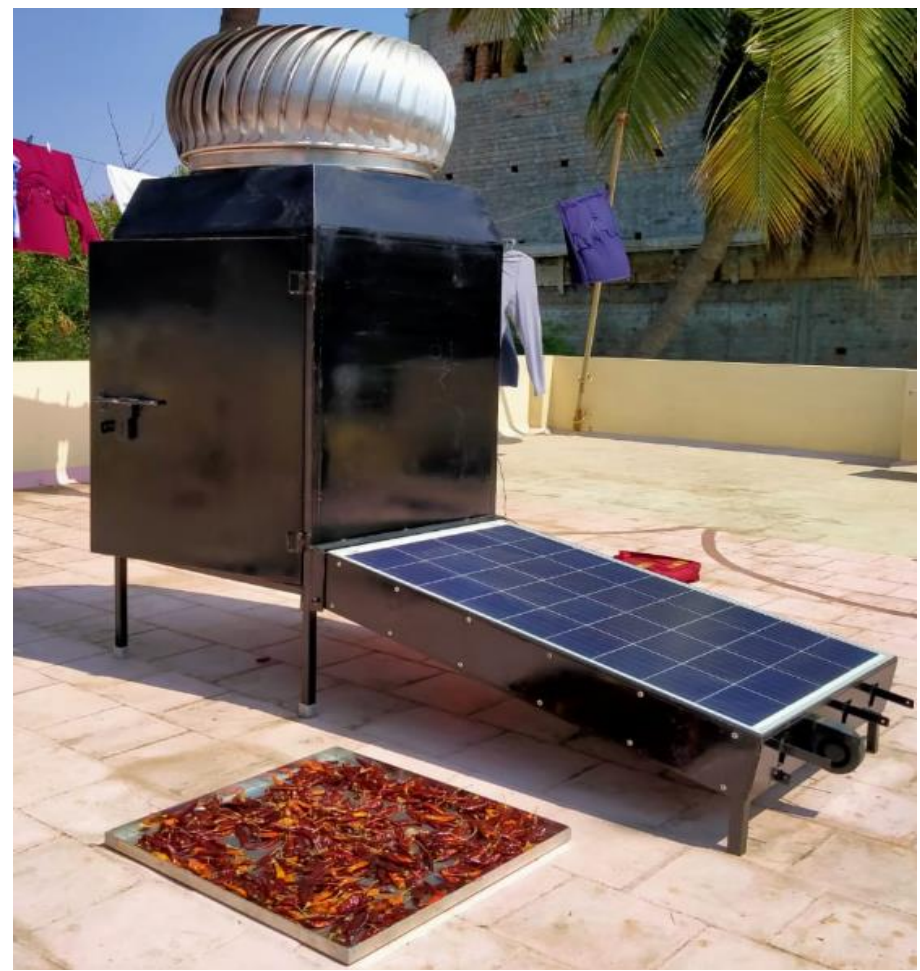

Figure 1. Pictorial view of open sun drying and solar dryer drying on Red chilli.

Table 1. Dimensions summary of the HCSD

System parameters 
Length of the panel

$1.115 \mathrm{~m}$

Width of the panel

$0.670 \mathrm{~m}$

Thickness of the panel

$0.035 \mathrm{~m}$

Area of the panel, $A$

$0.7471 \mathrm{~m}^{2}$

Open circuit voltage of solar panel, Voc

$18.98 \mathrm{~V}$

Short circuit current of solar panel, Isc

$5.26 \mathrm{~A}$

Slope of the solar panel surface

$13^{\circ}$

Length of the drying chamber

$0.700 \mathrm{~m}$

Width of the drying chamber

$0.690 \mathrm{~m}$

Height of the drying chamber

$1.050 \mathrm{~m}$

Fan power

18 Watts

\section{Operating parameters}

air velocity at the entry of the channel $(v)$

ambient temperature $\left(T_{a}\right)$

$1.2 \& 1.8 \mathrm{~m} / \mathrm{s}$

solar radiation $(G)$

$307-316 \mathrm{~K}$

$400-1100 \mathrm{~W} / \mathrm{m}^{2}$

\section{Methodology}

\subsection{Energy Balance and moisture content of the commodity}

The mass and energy balances of any open system or control volume at a steady state conditions could be calculated as given below [31].

$\dot{m}_{a i}=\dot{m}_{a o}$

Where, $\dot{\mathrm{m}}_{\mathrm{ai}}$ and $\dot{\mathrm{m}}_{\mathrm{ao}}$ represent the inlet and outlet mass flow rates of the solar hybrid collector with dryer respectively.

The mass conservation for the moisture content of the commodity could be taken in terms of mass flow of the moisture from the sea level, and $\dot{\mathrm{m}}_{\mathrm{mp}}$, and the inlet and outlet flow of specific humidities, $\omega_{\mathrm{ai}}$ and $\omega_{\mathrm{ao}}$, respectively, as follows,

$$
\dot{m}_{a i} \omega_{a i}+\dot{m}_{m p}=\dot{m}_{a o} \omega_{a o}
$$

The initial and final stage of moisture level of the particular commodity with respect to time $t$ which were designed with the assistance of following equations as follows [32].

$$
\begin{aligned}
& M_{o}=\frac{m_{i}-m_{d}}{m_{i}} \\
& M_{f}=\frac{m_{s}-m_{d}}{m_{s}} \\
& M_{t}=\frac{m_{t}-m_{d}}{m_{t}}
\end{aligned}
$$

Where, mi, Initial mass of the commodity $(\mathrm{kg})$, md, Mass of dry matter in the dryer $(\mathrm{Kg})$, ms, Mass of the dried commodity in the solar dryer $(\mathrm{Kg}), \mathrm{mt}$, Mass of the sample at time $\mathrm{t}(\mathrm{kg})$.

\subsection{Electrical Efficiency Performance}

Electrical efficiency performance of a PV panel could be determined as a ratio of electrical energy output of the PV panel to the solar energy (or) light energy falls on the solar panel which is carried out as given below [12, $13,33,34,35]$

$$
\eta_{e l}=\frac{V_{m p} I_{m p}}{\dot{S}}=\frac{\dot{E}_{e l}}{\dot{S}}
$$

Where, $\dot{\mathrm{E}}_{\mathrm{el}}$ is an outlet electrical power $(\mathrm{W}), \dot{\mathrm{S}}$ is a rate of solar energy falls on the solar panel (W).

$$
\dot{S}=G N_{s} N_{m} A_{\text {mod }}
$$

Where, $G=$ solar radiation, $\mathrm{W} / \mathrm{m}^{2}, N_{m}=$ number of modules in series per string, $N_{s}=$ number of strings, $A_{\text {mod }}$ $=\mathrm{PV}$ module area, $\mathrm{m}^{2}$.

$A_{\text {mod }}=\mathrm{PV}$ module area, $\mathrm{m}^{2}$. 
$A_{\text {mod }}=L_{1} L_{2}$

Where, $L_{l}=$ length of PV module, $\mathrm{m}, L_{2}=$ width of $\mathrm{PV}$ module, $\mathrm{m}$,

\subsection{Thermal Efficiency Performance}

Thermal efficiency performance has been conducted with various parameters such as heat energy generation $(\mathrm{KJ})$, area of the panel $\left(\mathrm{m}^{2}\right)$ and solar radiation intensity $\left(\mathrm{W} / \mathrm{m}^{2}\right)$. The following equations were compiled the finding of thermal performance of solar hybrid collector as given below $[11,12,13,36]$.

The equation of mass flow rate of air $(\mathrm{Kg} / \mathrm{s})$ is expressed by

$\dot{m}=\rho A_{m o d} v$

Where, $\dot{m}=$ mass flow rate of air, $\mathrm{kg} / \mathrm{s}, \rho=$ density, $\mathrm{kg} / \mathrm{m}^{3}, A_{\text {mod }}=\mathrm{PV}$ module area, $\mathrm{m}^{2}$,

$V=$ velocity of air, $\mathrm{m} / \mathrm{s}$.

$Q_{u}=\dot{m} C p\left(T_{\text {out }}-T_{\text {in }}\right)$

Where, $\mathrm{Cp}$ is a specific heat capacity of air $(\mathrm{KJ} / \mathrm{Kg} \mathrm{K})$ and Tin and Tout shows input and output fluid air temperatures in the solar hybrid collector, respectively. Further, thermal energy were generated by forced convection through mini fan as follows.

$$
\eta_{\text {ther }}=\frac{Q_{u}}{\left(A_{\text {mod }} G+P_{\text {fan }}\right)}
$$

Where, $\mathrm{P}_{\text {fan }},(\mathrm{W})$ is the fan power using to generate thermal energy or heat energy in the solar hybrid collector which can be used to dry the commodities in the solar dryer.

$$
\eta_{e l, t h e r}=\frac{\eta_{e l}}{C_{f}}
$$

$$
\begin{aligned}
& \eta_{\text {en,overall }}=\eta_{\text {ther }}+\frac{\eta_{e l}}{C_{f}} \\
& \eta_{\text {en,overall }}=\eta_{\text {ther }}+\eta_{e l, \text { ther }}
\end{aligned}
$$

Where, $\eta_{\text {el, ther }}$, electrical thermal efficiency, $\eta_{\text {el }}$ electrical efficiency, $\eta_{\text {en, overall }}$, overall energy efficiency, $\eta_{\text {ther }}$, thermal efficiency and $\mathrm{C}_{\mathrm{f}}$ is the conversion factor of the thermal power plant and its value may be taken as 0.36 for countries such as India.

\section{4. $\quad$ Results \& Discussions}

Hybrid collector with solar dryer (HCSD) has been performed various analysis on Red chilli. The performance tests were conducted on days with clear sky condition. In this study, various analysis were carried out such as electrical, thermal, electrical thermal, overall thermal efficiency of hybrid collector cum solar dryer. Further, removal of moisture from the Red chilli by solar dryer drying which were compared with open sun drying.

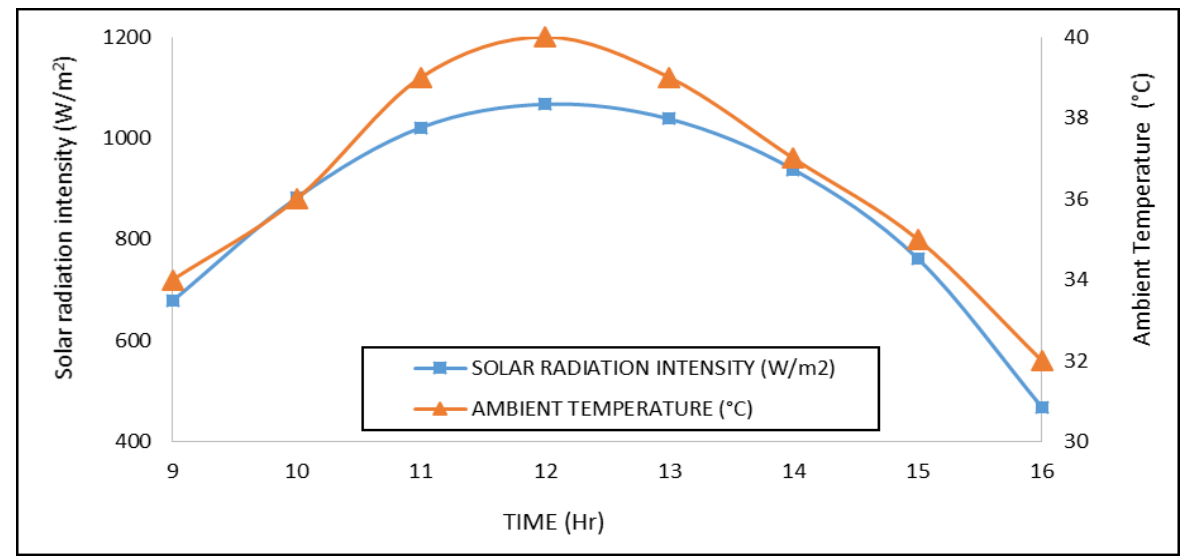

Figure 2. Average solar radiation and ambient temperature with time (hrs). 
Typical hourly values of average solar radiation and ambient temperature since $9 \mathrm{hr}$ to $16 \mathrm{hr}$ is revealed in Figure 2. The maximum solar radiation was found to be $1067 \mathrm{~W} / \mathrm{m}^{2}$ at $12 \mathrm{hr}$ and minimum solar radiation was found to be $468 \mathrm{~W} / \mathrm{m}^{2}$ at $16 \mathrm{hrs}$. Similarly, the maximum ambient temperature was found to be $40{ }^{\circ} \mathrm{C}$ at $12 \mathrm{hrs}$ and minimum ambient temperature was found to be $32{ }^{\circ} \mathrm{C}$ at $16 \mathrm{hrs}$ respectively. Solar radiation is always higher at midday and low in the morning and evening hours. On all test days, solar radiation range was from $468 \mathrm{~W} / \mathrm{m}^{2}$ to $1067 \mathrm{~W} / \mathrm{m}^{2}$. Evidently, the solar radiation and ambient temperature from $9 \mathrm{hr}$ to $16 \mathrm{hr}$ seems to be existing a dome-shaped structure as shown in Fig.2.

Typical hourly values of electrical efficiency and glazing surface temperature of HCSD since $9 \mathrm{hr}$ to $16 \mathrm{hr}$ is shown in Figure 3. The parameters such as maximum power point voltage $\left(\mathrm{V}_{\mathrm{mp}}\right)$, maximum power point current $\left(I_{m p}\right)$, solar radiation $(G)$ and area of the solar panel $\left(A_{\text {mod }}\right)$ were assessed during electrical energy $\left(\eta_{\mathrm{ELE}}\right)$ analysis. Evidently, from $9 \mathrm{hr}$ to $12 \mathrm{hr}$ there was increase in glazing temperature and decreased electrical efficiency then vice versa till $16 \mathrm{hr}$. It was observed that when glazing surface temperature was maximum, electrical efficiency was minimum between $11 \mathrm{hr}$ to $13 \mathrm{hr}$. Due to high glazing surface temperature, the electrical performance was very lower.

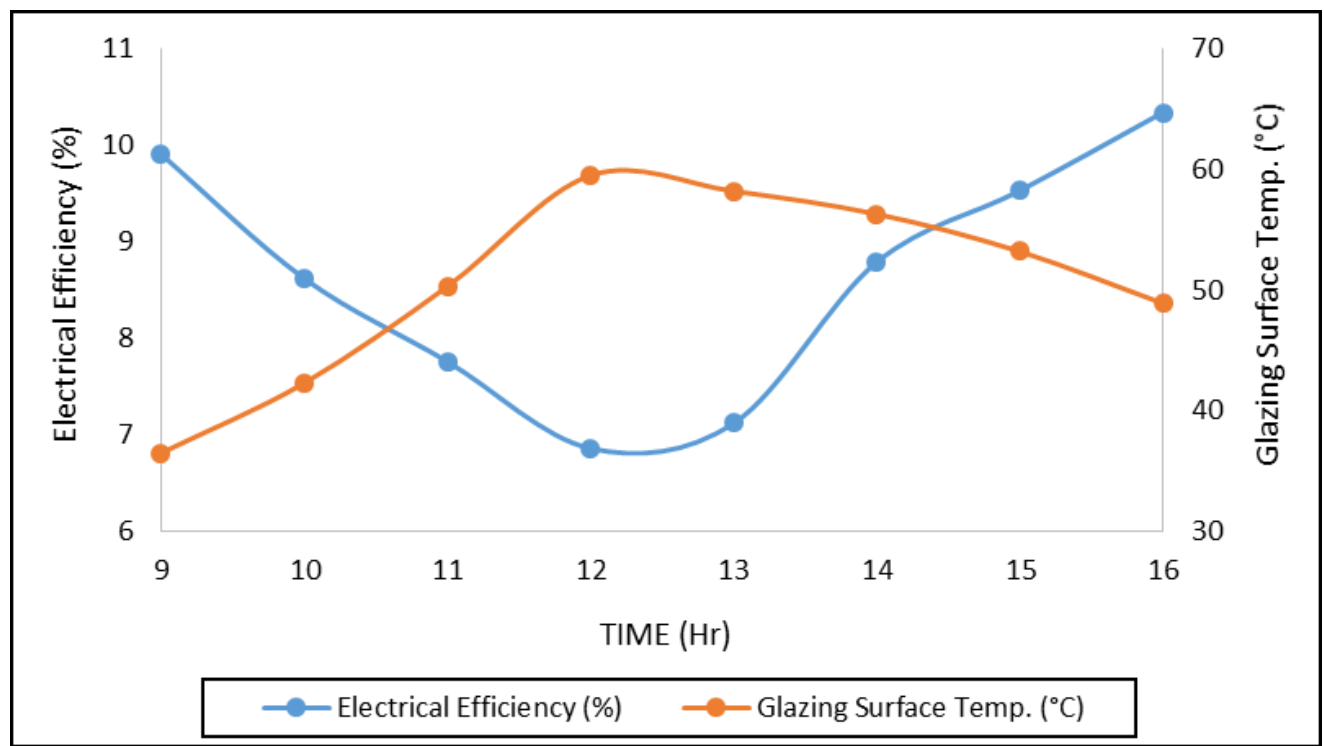

Figure 3. Electrical efficiency and glazing surface temperature of HCSD.

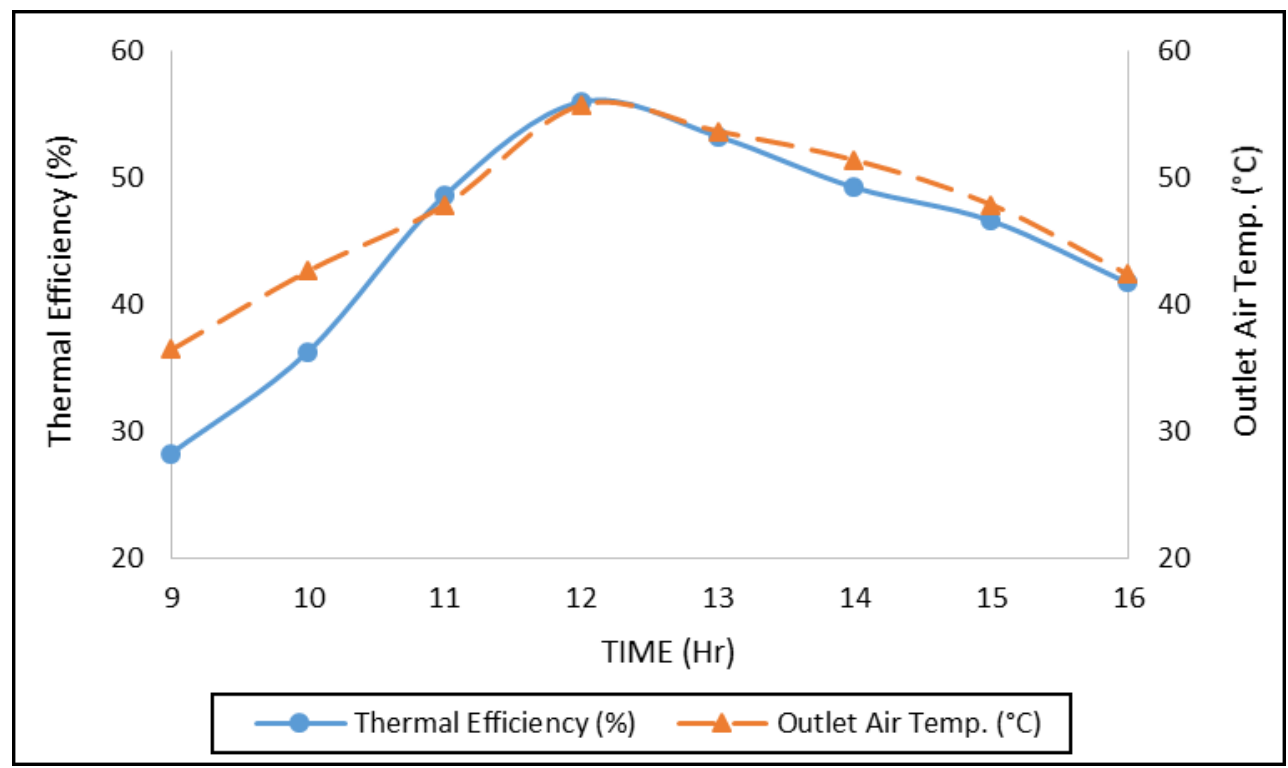

Figure 4. Thermal efficiency and Outlet air temperature of HCSD.

Typical hourly values of Thermal efficiency and Outlet air temperature of HCSD is exposed in Figure 4. Thermal efficiency $\left(\eta_{\text {ther }}\right)$ was determined based on the measured parameters such as difference in outlet and inlet air temperature $(\Delta T)$, mass flow rate of air $(\dot{\mathrm{m}})$, specific heat of air $\left(\mathrm{C}_{\mathrm{p}}\right)$, area of the solar panel $\left(\mathrm{A}_{\bmod }\right)$ and solar 
radiation $(\mathrm{G})$. The thermal performance increased with increase in air mass flow rate and solar radiation. Extracted more heat energy from the tedlar side which generated better performance of the system. The hourly variations of thermal efficiency Vs outlet air temperature of HCSD was calculated by using Eqs. 9 to 11 . Evidently, outlet air temperature was maximum between $12 \mathrm{hrs}$ to $14 \mathrm{hrs}$, due to maximum solar radiation available during those hours.

Typical hourly values of electrical thermal efficiency and glazing surface temperature of HCSD is shown in Figure 5. The equations (6 to 8 and 12) can be assisted to find out the electrical and electrical thermal efficiency of HCSD. This can be produced replication of electrical efficiency of HCSD which has been compared with glazing surface temperature. Evidently, when glazing surface temperature has been increased from 9 am to 4 pm, electrical thermal efficiency has been decreased as shown in Fig. 5.

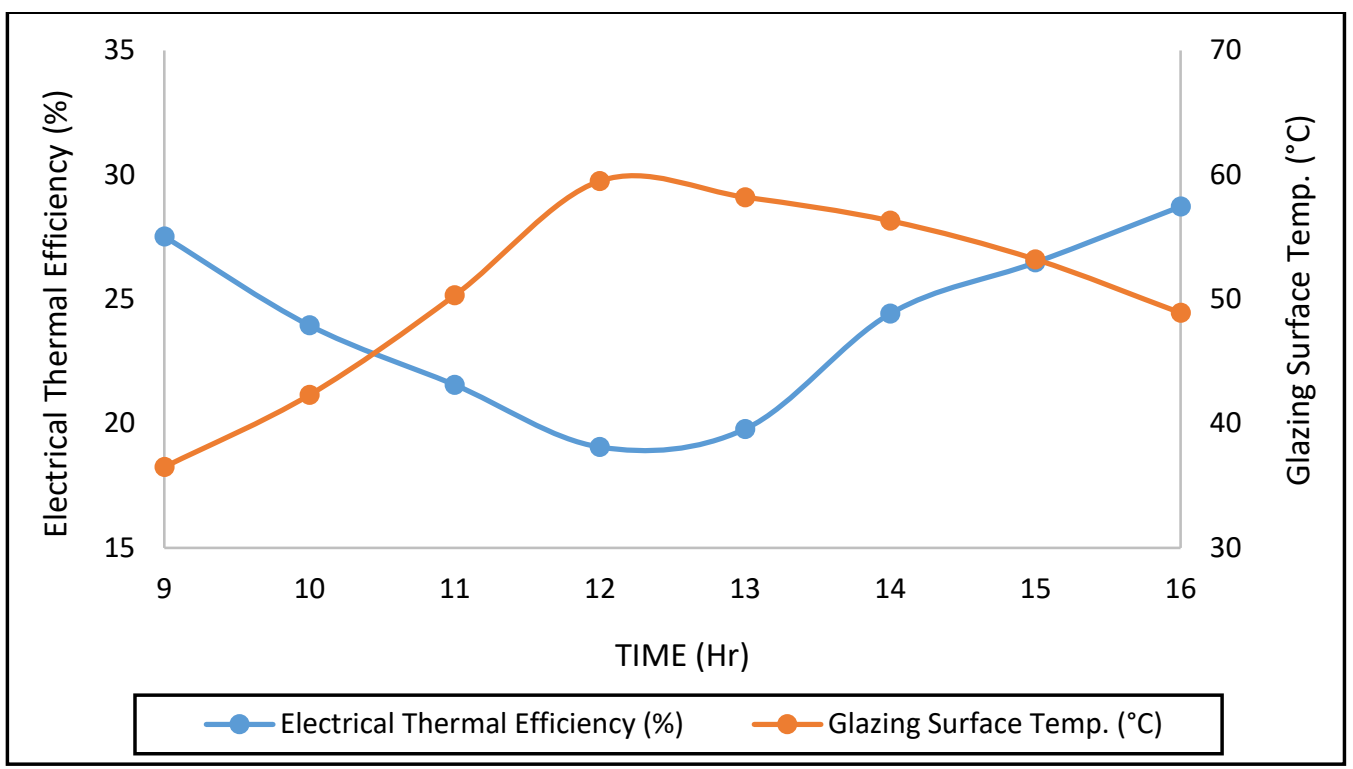

Figure 5. Electrical thermal efficiency and glazing surface temperature of HCSD.

Typical hourly values of overall thermal efficiency and glazing surface temperature of HCSD is revealed in Figure 6. Overall performance of Hybrid collector with solar dryer (HCSD) can be performed by equation 13 \& 14. In which all the performances such as electrical, electrical thermal, thermal efficiency were integrated.

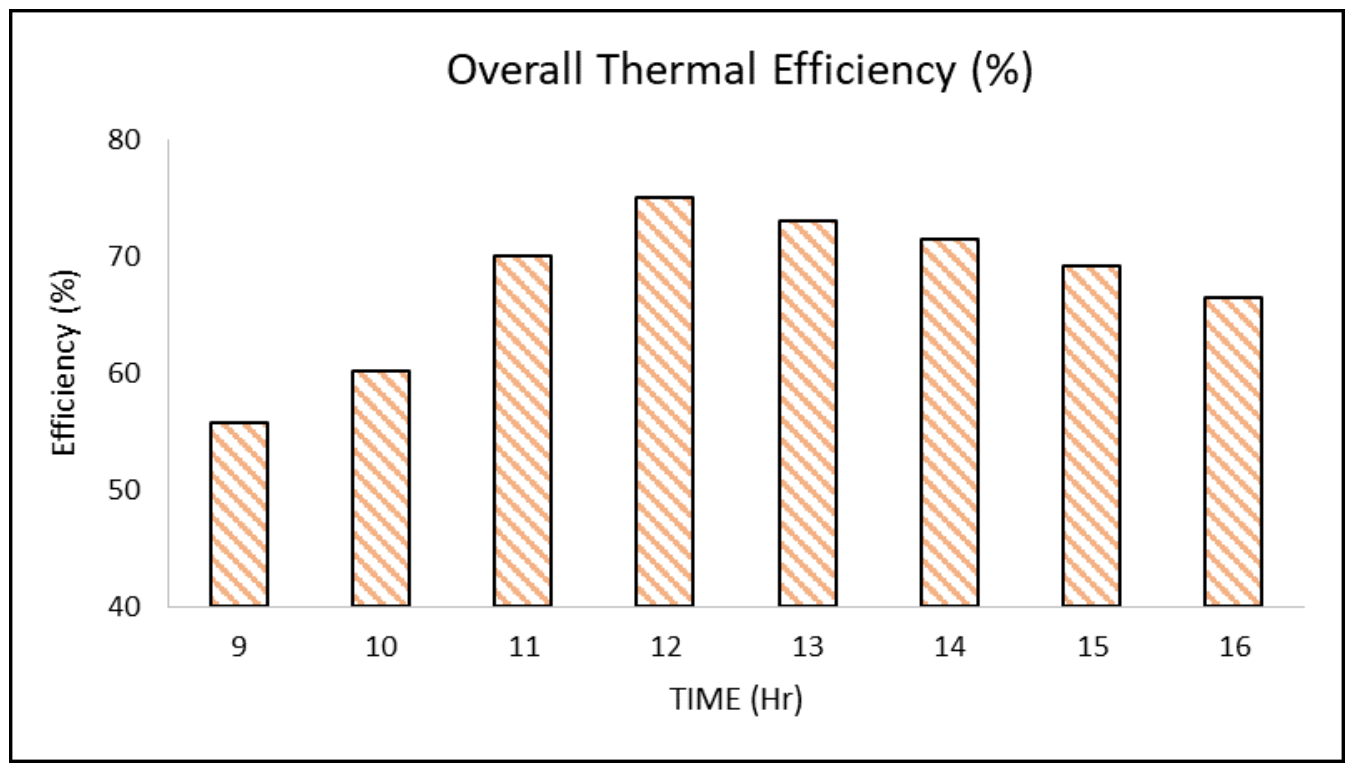

Figure 6. Overall thermal efficiency of HCSD.

Fig. 7. Shows the change in the moisture content of the solar and open sun dried chilli samples. The moisture content of the Red chilli was condensed from the initial value of 71.5\% (weight basis) to the final value of 16.2 $\%$ (weight basis) in $37 \mathrm{~h}$ and $76 \mathrm{~h}$ in the solar dryer drying and the open sun drying, respectively. 


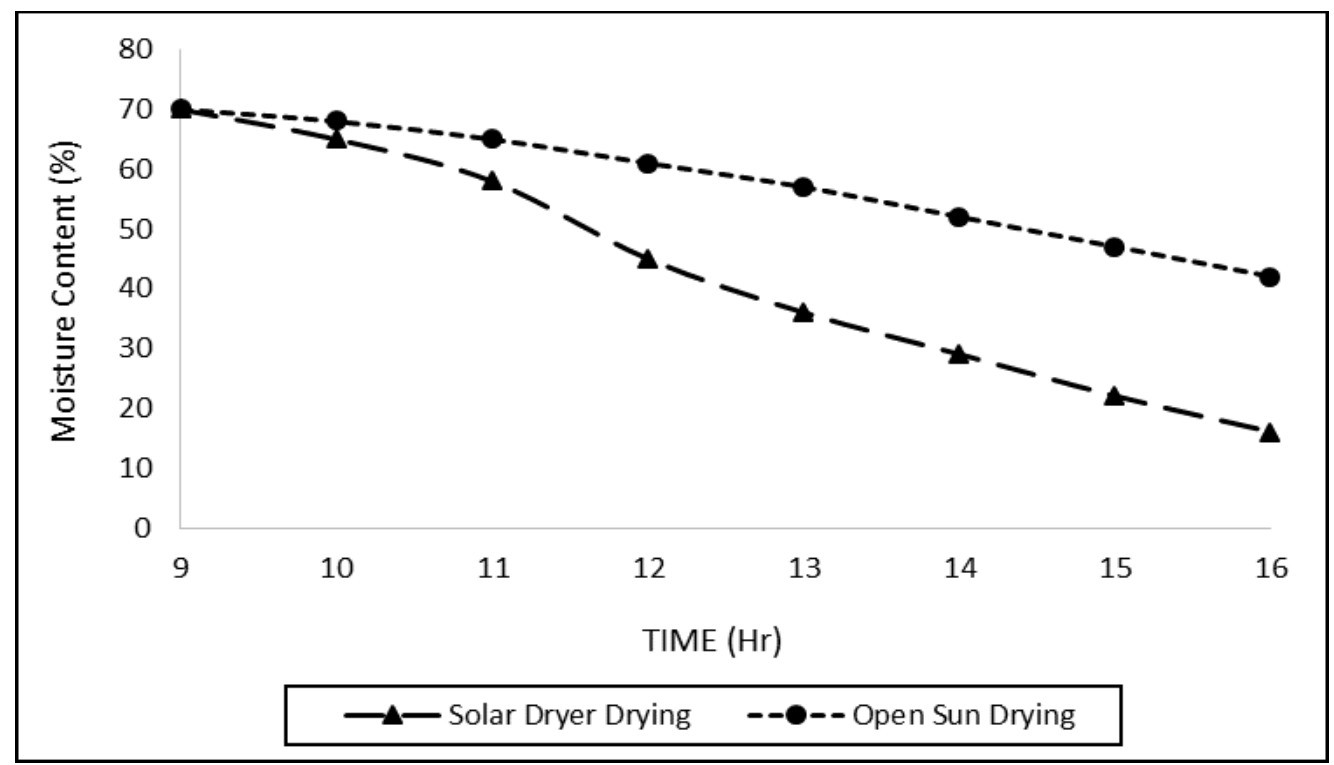

Figure 7. Average Change in the moisture content of the solar dryer drying and open sun drying.

The sun drying sample took $116.53 \%$ longer drying time in comparison with the sample dried in the newly developed HCSD. Further, the solar dried chilli was free from dirt and clean nature.

\section{Conclusion}

Comparative study of solar drying and open sun drying of Red chilli in a HCSD were provided following conclusions as given below.

* Electrical, electrical thermal, thermal efficiency and overall thermal efficiency were attained by HCSD such as $11.74 \%, 32.21 \%, 65.82 \%$ and $93.26 \%$ respectively. The performance of each component of the HCSD was evaluated in terms of the energy efficiencies.

* Twelve kg of red chilli was effectively dried in the HCSD in six consecutive sunny days at a specific location. The HCSD were achieved significantly better solar drying than open sun drying.

\section{References}

1. B.J.Brinkworth, B.M.Cross, R.H.Marshall, H. Yang, Thermal regulation of photovoltaic cladding, Solar Energy, 61 (1997) 169-178.

2. J. Ji, J. Han, T. Chow, H. Yi, J. Lu, W. He, W. Sun, Effect of fluid flow and packing factor on energy performance of a wall-mounted hybrid photovoltaic/water-heating collector system, Energy and Buildings, 38 (2006) 1380-1387.

3. E. Skoplaki, J.A. Palyvos, On the temperature dependence of photovoltaic module electrical performance: A review of efficiency/power correlations, Solar Energy, 83 (2009) 614-624.

4. A. Mohan, V.Saravana Karthika , J. Ajith , Lenin dhal , M. Tholkapiyan , "Investigation on ultra high strength slurry infiltrated multiscale fibre reinforced concrete", Materials Today : Proceedings, Volume 22, 904-911, 2020.

5. Parker, B.F., Lindley, M.R., Colliver, D.G., Murphy, W.E., 1993. Thermal performance of three solar air heaters. Sol. Energy 51 (6), 467-479.

6. M. Tholkapiyan, A.Mohan, Vijayan.D.S, A survey of recent studies on chlorophyll variation in Indian coastal waters, IOP Conf. Series: Materials Science and Engineering 993 (2020) 012041, 1 6.

7. Karim, MA., Hawlader, MNA., 2006. Performance investigation of flat plate, v-corrugated and finned air collectors. Energy 31 (4), 452-470.

8. Elshafei, E.A.M., Awad, M.M., El-Negiry, E., Ali, A.G., 2010. Heat transfer and pressure drop in corrugated channels. Energy 35 (1), 101-110.

9. Srimanickam. B, Vijayalakshmi. M. M \& Natarajan. E 2015, 'Thermal Analysis on Photovoltaic Thermal Hybrid System with Cooling Channel with V-Baffles', Indian Journal of Science and Technology, vol. 8, no. 36, pp 111-120. 
10. Srimanickam. B, Vijayalakshmi. M. M \& Natarajan. E., 2015, Experimental performance assessment of single glazing flat plate solar photovoltaic thermal (PV/T) hybrid system. Progress in Industrial Ecology, an International Journal, vol. 9, no. 2, pp. 111-120.

11. Gopalakrishnan, R., Mohan, A., Sankar, L. P., \& Vijayan, D. S. (2020). Characterisation On Toughness Property Of Self-Compacting Fibre Reinforced Concrete. In Journal of Environmental Protection and Ecology (Vol. 21, Issue 6, pp. 2153-2163).

12. Srimanickam. B, Vijayalakshmi. M. M \& Natarajan. E., 2018, 'Energy and exergy efficiency of flat plate PVT collector with forced convection', Journal of Testing and Evaluation, vol. 46, no. 2, pp. 1-15.

13. Srimanickam. B., \& Saranya. A., 2019 "Thermal performance of single glazing flat plate photovoltaic thermal hybrid system with various air channels," Journal of Testing and Evaluation, vol. 49, no. 3 .

14. Yadav S, Kaushal M, Varun, Siddartha. Nusselt number and friction factor correlations for so-lar air heater duct having protrusions as roughness elements on absorber plate. Exp Therm fluid Sci 2013; 44:34-41.

15. Chaube, Sahoo PK, Solanki SC. Analysis of heat transfer augmentation and flow characteristics of a solar air heater. Renew Energy 2006; 31: 317-31.

16. Lavanya Prabha, S., Gopalakrishnan, M., Neelamegam, M., Development of high-strength nanocementitious composites using copper slag, ACI Materials Journal, 2020, 117(4), pp. 37-46.

17. Karmare SV, Tikekar AN. Analysis of fluid flow and heat transfer in a grit roughened surface solar air heater using CFD. Sol Energy 2010; 84:409-17.

18. Yadav AS, Bhagoria JL. A numerical investigation of square sectioned transverse rib roughened solar air heater. Int J Therm Sci 2014; 79:111-3.

19. Kumar A, Kim M-H. Effect of roughness width ratios in discrete multi V-rib with staggered rib roughness on overall thermal performance of solar air channel. Sol Energy 2015; 119: pp.399-414.

20. Singh S, Singh B, Hans VS, Gill RS. CFD (computational fluid dynamics) investigation on Nusselt number and friction factor of solar air heater duct roughened with non-uniform crosssection transverse rib. Energy 2015; 84:509-17.

21. Dongxu J, Zhang M, Wang P, Shasha X. Numerical investigation of heat transfer and fluid flow in a solar air heater duct with multi V-shaped ribs on the absorber plate. Energy 2015;89: 178-90.

22. J.S. Sawhney, Rajesh Maithani, Sunil Chamoli., "Experimental investigation of heat transfer and friction factor characteristics of solar air heater using wavy delta winglets", Applied Thermal Engineering 117 (2017) 740-751.

23. Dongxu Jin, Jianguo Zuo, Shenglin Quan, Shiming Xu, Hao Gao., "Thermohydraulic performance of solar air heater with staggered multiple V-shaped ribs on the absorber plate", Energy 127 (2017) 68-77.

24. Deep Singh Thakur, Mohd. Kaleem Khan, Manabendra Pathak., "Performance evaluation of solar air heater with novel hyperbolic rib geometry" Renewable Energy 105 (2017) 786-797.

25. V.S. Hans, R.S. Gill, Sukhmeet Singh, "Heat transfer and friction factor correlations for a solar air heater duct roughened artificially with broken arc ribs" Experimental Thermal and Fluid Science 80 (2017) 77-89.

26. Adem Acir, Ismail Ata, Mehmet Emin Canlı, "Investigation of effect of 560 the circular ring turbulators on heat transfer augmentation and fluid flow characteristic of solar air heater" Experimental Thermal and Fluid Science 77 (2016) 45-54.

27. Anil P. Singh, Varun, Siddhartha, "Heat transfer and friction factor correlations for multiple arc shape roughness elements on the absorber plate used in solar air heaters" Experimental Thermal and Fluid Science 54 (2014) 117-126.

28. Omer, K.A., Zala, A.M., 2018. Experimental investigation of PV/thermal collector with theoretical analysis. Renew. Energy Focus 27, 67-77.

29. Slimani, M.E.A., Amirat, M., Kurucz, I., Bahria, S., Hamidat, A. and Chaouch, W.B., 2017. A detailed thermal-electrical model of three photovoltaic/thermal (PV/T) hybrid air collectors and photovoltaic (PV) module: Comparative study under Algiers climatic conditions. Energy conversion and management, 133, pp.458-476.

30. Hasanuzzaman, M., Malek, A.B.M.A., Islam, M.M., Pandey, A.K. and Rahim, N.A., 2016. Global advancement of cooling technologies for PV systems: A review. Solar Energy, 137, pp.25-45.

31. Cristiana Brasil Maia, André Guimarães Ferreira, Luben Cabezas-Gómez, Janaína de Oliveira Castro Silva, Sérgio de Morais Hanriot. Thermodynamic analysis of the drying process of bananas in a small-scale solar updraft tower in Brazil. 10.1016/j.renene.2017.07.102. 
32. D.V.N. Lakshmi, P. Muthukumar, Apurba Layek, Prakash Kumar Nayak, Drying kinetics and quality analysis of black turmeric (Curcuma caesia) drying in a mixed mode forced convection solar dryer integrated with thermal energy storage. 10.1016/j.renene.2017.12.053.

33. Alta, D., Bilgili, E., Ertekin, C. and Yaldiz, O., 2010. Experimental investigation of three different solar air heaters: Energy and exergy analyses. Applied Energy, 87(10), pp.2953-2973.

34. Esen, H., 2008. Experimental energy and exergy analysis of a double-flow solar air heater having different obstacles on absorber plates. Building and Environment, 43(6), pp.1046-1054.

35. Akpinar, E.K., and Koçyiğit, F., 2010. Energy and exergy analysis of a new flat-plate solar air heater having different obstacles on absorber plates. Applied Energy, 87(11), pp.3438-3450.

36. Ali Heydaria, Mehrdad Mesgarpour, Experimental analysis and numerical modeling of solar air heater with helical flow path, Solar Energy 162 (2018) 278-288. 